\title{
How popular are social investment policies really? Evidence from a survey experiment in eight Western European countries
}

\author{
NEIMANNS, Erik; BUSEMEYER, Marius R.; GARRITZMANN, Julian Leonce \\ Post-print version (final accepted version) of article - European sociological review, \\ 2018
}

\begin{abstract}
:
The concept of the social investment welfare state has received a lot of attention and support both from academics and policy-makers. It is therefore commonly assumed that policies such as investing in education or family services would also receive significant support from the mass public. While there are some indications of this, existing comparative surveys of public opinion usually do not take into account how citizens perceive and react to policy trade-offs, i.e. how they respond when forced to prioritize between different types of social policies, which is more realistic given budget constraints. This paper presents original data from a representative survey of public opinion in eight Western European countries, studying how support for social investment policies changes when additional spending on these policies would have to be financed with cutbacks in other parts of the welfare state. The central findings are that citizens generally dislike being forced to cut back one type of social spending in order to expand another, but there is a significant degree of variation across individuals. Material self-interest and ideological predispositions as well as their interaction help understanding differences in the acceptance of these trade-offs. The findings have important implications for the political viability

of social investment policies. Political parties aiming to expand social investment in a context of fiscal austerity are confronted with different and distinct electoral constraints and challenges given the respective preferences of their electorates.
\end{abstract}

\section{Keywords}

Policy trade-offs, social investment, education policy, welfare state, attitudes, public opinion. 


\section{Introduction}

In recent years, the notion of the "social investment" model of the welfare state has gained much attention both among scholars and policy-makers (Bonoli, 2013; Hemerijck, 2013, 2017; Morel et al., 2012). Social investment policies can be defined as policies geared at creating, mobilizing, or preserving human skills (Garritzmann et al., 2017: 36ff.), e.g. education, active labor market, or childcare policies. These 'new' types of social policies are often contrasted with more traditional social policies such as pensions, unemployment benefits, or health care (Vandenbroucke and Vleminckx, 2011), which are directed at compensating beneficiaries ex post for socio-economic and labor market losses.

Many of the traditional social transfer and insurance policies entail a significant degree of redistribution and are therefore associated with a high degree of income-related conflict on the level of welfare state attitudes (Busemeyer et al., 2009; Cusack et al., 2006; Rehm, 2009). In contrast, social investments tend to provide relatively more benefits to the affluent middle and upper income classes (Van Lancker 2013). Consequently, social investment policies could be widely popular and less contested across the class divide. Existing scholarship using available survey data confirms that large majorities in advanced industrial democracies support higher public spending on education (Ansell, 2010; Busemeyer, 2012; Garritzmann, 2015) and government responsibility for the provision of childcare (Bonoli 2013; Meuleman and Chung, 2012; Busemeyer and Neimanns, 2017).

This paper takes this literature as point of departure. We probe the robustness of public support for social investment relative to social transfer policies. The motivation for this is 
the supposition that support for social investments might be vulnerable to the dominance of short-term over long-term concerns. While social investments might have significant benefits in the future, expanding these policies creates short-term costs, particularly if other parts of the welfare state have to be cut back. In an age of "permanent austerity" (Pierson, 2001) policy-makers are regularly confronted with policy trade-offs requiring cutbacks in some part of the welfare state in order to expand other parts such as the social investment pillar. A significant shortcoming of existing surveys on education and other social policies, however, is that the question wording used in these surveys does not force respondents to choose and prioritize between different policy areas. This might contribute to a severe overestimation of the extensiveness of support for social investment policies.

In order to address this shortcoming, this paper exploits a novel dataset from a representative survey of public opinion in eight Western European countries (AUTHORS, 2017). An innovative component in this survey is that it explicitly takes into account policy trade-offs when measuring the extent of public support for social investment policies. Confronting respondents with different possibilities to prioritize among various social policies in a quasi-experimental setting, our analysis reveals that public support for social investment policies drops precipitously once trade-offs are taken into account. Furthermore, we find that material self-interest becomes a stronger determinant of policy preferences when moving from unconstrained to constrained settings. Finally, we also explore interaction effects between self-interest and ideology, showing that material selfinterest related to spending trade-offs is a more important determinant of attitudes for those identifying with a right-wing ideology compared to those sympathizing with the left. 
As we discuss in the conclusion, this is an important and challenging finding for the future of the social investment state.

\section{Literature review and research gap}

The analysis of welfare state attitudes has become a growing field in comparative welfare state research (Kumlin and Stadelmann-Steffen [2014] as well as Svallfors [2012] provide overviews). In general, earlier studies have focused more on identifying the micro-level determinants of attitudes and policy preferences (see, for instance, Hasenfeld and Rafferty, 1989), while more recent work shifts attention towards exploring the feedback effects of macro-level policies and institutions (Jaeger, 2009; Jakobsen, 2010; Jordan, 2013). In the present paper, we are mainly concerned with studying the determinants of attitudes on the micro-level, however.

Simplifying greatly, the pertinent literature on the micro-level determinants of attitudes can be divided into two categories: First, supporting the rational choice paradigm, materialistic self-interest has consistently been shown to shape preferences: People support those welfare policies from which they or their close relatives (expect to) benefit. Those not benefitting and those paying for these benefits, in turn, tend to be opposed. The literature discusses several indicators of self-interest, for example individuals' income, educational background, labor market status and skill sets, age, welfare state beneficiary status, and labor market risk (Busemeyer et al., 2009; Cusack et al., 2006; Häusermann et al., 2015; Iversen and Soskice, 2001; Rehm, 2009; Rehm et al., 2012). More recently, panel data has been used to demonstrate the causal effect of personal experiences of material deprivation on social policy preferences (Brooks and Manza, 2013; Jaeger 2006; Margalit, 2013; Naumann et al., 2016; Owens and Pedulla, 2014), but results remain inconclusive. 
Besides material self-interest, secondly, values, norms, and ideological predispositions have been found to influence welfare state attitudes (Kangas, 1997; Lupu and Pontusson, 2011). For example, Lupu and Pontusson (2011) argue that other-oriented attitudes matter for redistribution preferences, i.e. people are not only self-oriented but also altruistic. Moreover, social policy preferences are also driven by non-materialistic factors such as religious beliefs (De La 0 and Rodden, 2008) and by respondents' perceptions of "deservingness", i.e. how worthy of support they perceive particular beneficiaries to be (van Oorschot, 2006). Finally, and maybe most importantly, this literature consistently reports that people's ideological position is strongly related to their social policy preferences. A newer literature adds the claim that materialistic self-interest can be moderated by ideological positions (Margalit, 2013), an important argument that we also seek to test further.

Despite these efforts, a major research gap in the existing literature on welfare state attitudes is that there is hardly any work on the issue of trade-offs between different welfare policies, particularly regarding 'old' compensatory versus 'new' social investment policies. A partial exception is Boeri et al. (2001), who confronted respondents in four countries with policy trade-offs, but only for the case of pension policies. In an earlier study, Hansen (1998) analyzes public opinion data for the case of the United States. Both studies provide evidence for the general point, prominently discussed by Pierson (2001) as well as by Brooks and Manza (2006), that citizens dislike cutbacks in welfare state spending and express strong support for the maintenance of the current status quo. Kuklinski et al. (2001) analyze policy trade-offs in health care for the case of the US, but 
their study deals with the role of information provision and motivation for trade-off choices, not with actual fiscal constraints of policy-making.

This gap in research, which is ultimately related to missing survey data on the notion of trade-offs, is significant because studying trade-offs on the level of individual policy preferences has very relevant implications for policy-making and assessments about the political viability and legitimacy of the social investment model of the welfare state. So far, analyses of the transformation of European welfare states towards the social investment model have mostly been confined to the macro-level of policy-making (Bonoli, 2013; Hemerijck, 2013; Morel et al. 2012, but see Häusermann et al., 2015), but it remains unclear to what extent this gradual shift reflects prevailing public attitudes. It might well be the case that public demand for social investment policies - responding to "new social risks" such as single parenthood or skills obsolescence (Bonoli, 2007; Esping-Andersen, 2002) - is robust and significant, and citizens are in fact willing to accept cutbacks in the more traditional pillars of the welfare state. Vice versa, recent policy changes might not be reflected on the level of attitudes at all, which could indicate a certain lack of responsiveness on the part of policy-makers, employing social investment reforms to 'sugarcoat' unpopular retrenchment. The focus of the present paper is to address this gap by adding new empirical information on public opinion about trade-offs for a representative sample of European countries. Our aim is to shed light on political preferences towards policy trade-offs at the individual level, studying particularly the interplay of material self-interest and ideological orientations..

\section{Attitudes towards social policy trade-offs and their determinants}


Before presenting a set of testable hypotheses, we briefly clarify our understanding of a "trade-off" on the level of individual preferences, which centers on the idea that citizens are forced to choose between two different competing policies: expanding one of these policies necessarily implies cutting back the other. Of course, this is a particular and therefore imperfect conception of a policy trade-off because, instead of trading one policy for another, citizens could be willing to accept more taxes or higher levels of public debt to finance additional spending. These are possibilities we explore in different, but related work, using another set of questions from the same survey (AUTHORS, 2017), showing that citizens in fact prefer to accept higher taxes or higher levels of public debt rather than cutting back spending in other parts of the welfare state. Increasing taxes or debt levels may, however, not always be feasible in practice because of fiscal constraints associated with Europeanization and economic globalization (Genschel, 2004) as well as because of a political discourse dominated by concerns about austerity and debt reduction (Blyth, 2013; Haffert and Mehrtens, 2015).

In the present paper, we therefore deliberately focus on trade-offs between different policy areas in order to better understand the dynamics underlying redistribution within the welfare state, which may be different from conflicts about its general size. In order to measure citizens' attitudes towards trade-offs, we rely on original public opinion survey data in eight European countries (details below) that forces respondents to choose between the expansion of social investment policies (education and family policies) to the detriment of social insurance and transfer policies (unemployment benefits and pensions). It is a legitimate question to ask to what extent our set-up and the implied notion of a 'trade-off' adequately reflects decision-making in the real world. Confronting survey respondents with a fixed set of choices always entails the danger of pre-maturely 
identifying patterns in public opinion, whereas "non-attitudes" (Berinsky, 2017) might dominate in the real world. Previous research found that citizens might hold conflicting preferences such as a preference for a more generous welfare state and lower taxes (Citrin, 1979; Giger and Nelson, 2013).

In spite of these limitations, we believe that our set-up adequately mirrors real-world challenges in the transformation of existing welfare states towards the social investment model. By comparing public support for social investment policies in constrained (i.e. with policy trade-offs) and unconstrained settings (i.e. without trade-offs), our analysis provides robust estimates of the upper and lower bounds for the extensiveness of support. While fiscal constraints in the real world of policy-making are rarely as binding as in our constructed set of limited choices, they are never fully absent either. We acknowledge that our construction of policy trade-offs does not represent the 'full menu' of potential policy alternatives. In fact, it is logically impossible to try to model all potential policy options, even when using tools that get closer to capturing multidimensional preferences, like conjoint analyses/factorial surveys, as the number of potential policy options and their combination is infinite. Consequently, we consider our analysis as a complement to existing studies rather than a full-scale replacement.

Of course, it might be argued that solving trade-offs between conflicting public demands is the task of policy-makers, not citizens. But we believe that studying citizens' reactions to trade-off scenarios is a worthy and important enterprise, because a permanent mismatch between policy-makers' actions and citizens' preferences could contribute to a decline in the legitimacy of democratic decision-making and declining levels of political trust. Furthermore, the limited evidence from existing studies on fiscal trade-offs 
(AUTHORS, 2017; Hansen, 1998; Kuklinski, et al. 2001) shows that citizens are well able to make informed and rational choices in these situations, as trade-offs "cause respondents to stop and think" (Hansen, 1998: 519). In the following, we develop a set of testable hypotheses, which guide the following subsequent empirical analysis.

\section{Perceptions of trade-offs}

Our first expectation is that citizens - just like politicians - dislike being confronted with trade-offs. Nobody likes making hard choices, particularly if they imply negative costs for oneself. Numerous theories in social psychology back this notion, for example cognitive dissonance theory, which argues that individuals try to avoid choice that would conflict with their ideal-level preferences, as this would cause them psychological discomfort (Festinger 1957; Elliot and Devine, 1994). Assuming that a considerable share of individuals might prefer both social investment and compensatory social policies, individual basic epistemic motivation to avoid ambiguity should lead them to reject policy proposals that conflict with their ideal preferences (Jost et al., 2009). This implies that

public support for the expansion of a particular social policy should drop significantly when moving from an unconstrained setting with no trade-off to a setting where spending increases would require cutbacks in other welfare areas (Hypothesis 1).

Furthermore, we expect variation across policy areas, i.e. different kinds of trade-offs. For example, we expect different dynamics in an "education vs. pension" trade-off than in an "education vs. unemployment benefits" trade-off. This variation might be related to variation in perceived "deservingness" (Van Oorschot, 2006) of different welfare beneficiary groups: The unemployed can be expected to be perceived as less deserving than retired persons or families with children for two reasons: Firstly, they are believed 
to be able to work themselves out of their predicament (Van Oorschot's "control criterion"), whereas retired persons and young families cannot do the same because of their dependency on the welfare state. Secondly, pensioners are perceived to be more deserving as they have contributed more themselves ("reciprocity criterion") and are perceived as being "closer" to the average respondent ("identity criterion").

Besides the normative implications, the "deservingness" argument also has a materialist, rational component, as individuals are likely to be more supportive of welfare state services and transfers, which they expect to need themselves in the future. Everybody turns old, but the risk of unemployment is more concentrated on certain groups (Busemeyer et al., 2009). Furthermore, the duration of personal experiences with the benefits and services of the welfare state differs across policies, as individuals (in Western Europe) have much longer personal experiences with the education system, whereas family policies targeted at families with small children cover a much shorter time-span. Hence, cutbacks in pensions are probably less popular than cutbacks in unemployment spending, and spending increases on education can be expected to be more popular than spending increases on family policies for parents with small children (Hypothesis 2).

\section{Material self-interest}

Besides variation across policy areas, we expect variation across individuals in citizens' perceptions of and reactions to trade-offs. We hypothesize that this micro-level variation in attitudes is related to material self-interest and that the explanatory power of indicators of self-interest will increase once we move from an unconstrained to a constrained (trade-off) scenario (Hypothesis 3). The simple reason is that citizens have become used to (and might even be dependent on) the provision of a large set of welfare 
services and benefits, which they would not want to give up even if other parts of the welfare state were expanded in exchange.

Thus, we focus on beneficiary status as an indicator of material self-interest here, but include additional variables related to material self-interest such as household income and age as control variables in the analysis. This implies, for instance, that pupils and students support increases in education spending and are willing to cut compensatory spending on unemployment and pensions to achieve this. Of course, students might well become unemployed in the future and they will surely turn old at some point, but the immediate short-term benefits of increasing spending on education might outweigh the rather diffuse costs of cutting transfers for the unemployed and pensioners. The same logic applies to parents of young children, whom we expect to support increases in public spending on families and education. In contrast, the unemployed should oppose more spending on social investments when this implies cutting back unemployment benefits. Finally, pensioners should oppose social investment expansion when this necessitates cutbacks in old-age pensions.

As hinted at above, we also posit that the explanatory power in terms of statistical significance and effect size for indicators of material self-interest increases when moving from an unconstrained to a constrained (trade-off) scenario. In the constrained scenario, citizens supporting the expansion of a particular policy are also forced to accept cutbacks in other social policies. This reduces the size of the group supporting expansion (see Hypothesis 1 above), but it also changes the composition of this group. It is plausible to assume that those supporting the expansion of a particular policy in spite of cutbacks will be those with the strongest self-interest in that policy. In contrast, those who stop supporting the policy will be respondents whose support might have been more an 
expression of general support for the welfare state before rather than the particular policy in question (Roosma, et al. 2013).

\section{Ideological predispositions}

In addition to material self-interest, we expect that ideological predispositions matter. An often-discussed problem in the study of the effects of norms and values on attitudes is endogeneity: When assessing the impact of ideology on welfare support it is difficult to disentangle the direction of causality, in particular in cross-sectional surveys. Hence, statistical associations should be interpreted as correlational relations rather than causal statements.

Since the dependent variable concerns trade-offs, which should elicit a prioritization between respondents' relative policy preferences, we expect responses to be nested in individuals' wider ideological belief systems (Zaller, 1992; Jost et al., 2009). However, the theoretical expectations related to ideological predispositions are not straightforward. For instance, people supporting social spending in general are likely to favor compensatory and social investment spending. While this relationship might seem rather trivial, it is difficult to deduce what this would imply for people's preferences on policy trade-offs, as both supporters and opponents of the welfare state might oppose expanding one spending area at the expense of another, but for different reasons: Individuals identifying with a left-wing ideology could object to being forced to choose between different types of social spending, which - in an unconstrained setting - they would both support. Vice versa, respondents subscribing to a right-wing ideology could be opposed to spending increases in general, even if they would partly be financed with cutbacks in other parts of the welfare state. However, as social investment policies tend to be less redistributive compared to many social transfers and therefore tend to benefit the 
(upper) middle class (Vandenbroucke and Vlemnickx, 2011), right-wing supporters could be less opposed to recalibrating the welfare state from classical redistributive policies towards a more investment-oriented and less redistributive model (Hypothesis 4). We expect cognitive dissonances to accept policy trade-offs to be the strongest for left-wing voters who should favor higher and more redistributive public spending. The influence of ideology should be particularly pronounced for policy proposals expanding education spending and for those cutting highly redistributive spending on unemployment benefits. For policy trade-offs expanding more redistributive social investment spending (financial support and public services for families; cf. Maldonado and Nieuwenhuis, 2015) and cutting less redistributive compensatory spending (pensions; Busemeyer et al., 2009), the effects of ideology should cancel out to some extent. ${ }^{\mathrm{i}}$

Furthermore, adapting Margalit's (2013) argument we hypothesize that ideological predispositions moderate the association between material self-interest and support for social investment in the trade-off scenarios. We expect that when confronted with a policy trade-off, materialistic self-interest plays a less important role for left-wing voters, because they are more solidaristic with all disadvantaged social risk groups and therefore oppose sacrificing benefits for one group to expand benefits for another. Thus, we expect that for left-leaning respondents the effect of their beneficiary status on their preferences is attenuated. Right-leaning citizens, in contrast, might be less opposed to recalibrating benefits (as discussed above) and their self-interest might be less attenuated by their ideological position. In sum, Hypothesis 5 posits an interaction effect between material self-interest and ideology. If this reasoning is true, it implies - at first glance counterintuitively - that if in times of "permanent fiscal austerity" (Pierson, 2001) the expansion of social investment is only possible at the expense of other spending, the "turn" towards 
the social investment state is in fact more supported (or at least more willingly accepted) by right-leaning individuals. For them, the associated ideological costs of ending up in a potentially less redistributive welfare state model are lower.

\section{Research design}

The research gap related to individual-level preferences towards trade-offs identified above is at least partly due to the lack of data on these issues as well as on social investment more generally in the existing comparative surveys like the International Social Survey Programme (ISSP), the European Social Survey (ESS), or the Eurobarometer (for details on this discussion and an overview of our survey, see AUTHORS, 2017). Thus, we conducted an original survey in eight European countries: Denmark, France, Germany, Ireland, Italy, Spain, Sweden, and the UK. Unfortunately, due to funding constraints, no Eastern or non-European countries could be included. Hence, the analysis is restricted to Western Europe, but covers a wide variety of countries from all 'worlds of welfare' in Western Europe here, thereby enhancing representativeness and external validity. In each country, we surveyed a representative sample of 1,000 to 1,500 adult individuals (aged 18-99), overall 8,905 individuals. The survey was conducted by a professional survey-institute via computer-assisted telephone interviewing (CATI) and fulfills all standards of a high-quality survey. Following pre-tests in February 2014, the main fieldwork took place mid-April to early-June $2014^{\mathrm{ii}}$.

\section{Dependent variables}

To test our theoretical expectations, we randomly split the sample into four groups in each country (Table $C$ in the Appendix shows that the randomization was successful as the groups are statistically indistinguishable on important covariates). The split in four, 
equally sized groups and random assignment to these groups are necessary to avoid statistical artifacts (and therefore wrong conclusions): If we had asked everybody these four questions, respondents might tend to reply in a similar fashion to these questions independent of their real preferences and/or they might show effects of survey fatigue or learning, leading to potential biases. Respondents thus see one, and only one, of the following statements (we add emphasis here to highlight the differences for the readers):

Q1: "Imagine the [COUNTRY] government plans to increase spending on education by $10 \%$ and wants to finance this by cutting the benefits for the unemployed."

Q2: "Imagine the [COUNTRY] government plans to increase spending on education by $10 \%$ and wants to finance this by cutting old age pensions."

Q3: "Imagine the government plans to enact reforms involving a 10\% increase in the budget for financial support and public services for families with young children; and wants to finance this by cutting the benefits for the unemployed."

Q4: "Imagine the government plans to enact reforms involving a 10\% increase in the budget for financial support and public services for families with young children; and wants to finance this by cutting old age pensions."

The statements confront respondents with four policy trade-offs: education and family support, on one hand, and unemployment benefits and pensions, on the other. We chose education and financial support and public services for families with young children as prime examples of social investment policies, as they seek to "create, mobilize, or preserve skills" (Garritzmann et al., 2017: 37) of children or their parents. Benefits for the unemployed and old-age pensions, in contrast, are typical examples of compensatory social policies. We can therefore analyze whether and why respondents prefer social investment or compensatory policies as well as differentiate further between two types of 'old' and 'new' welfare policies. 
We specified a "10\% increase" in the question framing for several reasons. First, this specification makes the policy options more concrete and tangible for respondents. Second, it increases the likelihood that respondents think in roughly similar terms about the proposed policy change. Speaking only about spending increases without providing a measuring yardstick, some respondents might think of a 1\%-increase while others imagine a $20 \%$-change. Of course, the "10 percent" figure is arbitrary to some extent and furthermore implies substantially different amounts of money across policy fields (e.g., pension expenditure is significantly higher than education spending) and countries. However, for our purpose it is not advisable to include different actual spending figures in the questions, since this increases the survey's administrative complexity and compromises its comparability. Hence, we have to assume that respondents take the $10 \%$ figure as a rough proxy signal for a non-trivial but realistic policy change.

We used the answers to the four split sample questions to create four dependent variables: Those supporting education spending (combining Q1 and Q2), those supporting spending on families with young children (Q3 and Q4), those accepting cutbacks in unemployment spending (Q1 and Q3) and, finally, those accepting cutbacks in pension spending (Q2 and Q4). By partially pooling the split-sample questions we can highlight the specific characteristics of each of the four policy fields regarding cuts and expansions and get an increased sample size for each single model leading to more robust estimates of the coefficients. All models include dummies for sub-group assignment.

For each question, we offered five answer categories: "strongly agree", "agree", "neither agree nor disagree", "disagree", "strongly disagree”. Moreover, two residual categories were included: "Don't know" and "No answer". Thus, we are measuring spending 
preferences relative to the status quo, not in absolute terms (cf. Kumlin, 2014). A disadvantage of this commonly used 5-point Likert-scale is that respondents might choose the category "neither agree nor disagree" for different reasons (Goerres and Prinzen, 2012). Admittedly, in our case, it is difficult to pin down exactly why respondents would remain undecided ("neither nor") towards a reform proposal: They might indeed reject the proposed spending shift between policy areas or they might simply dislike being forced to choose between different types of spending and reject the implied notion of welfare state reform as a zero-sum game.

For this reason, we focus on those respondents who state a clear preference towards agreement of the proposed trade-off scenario against all other respondents. A reassuring indication that we are measuring meaningful responses rather than non-attitudes is that there are only few respondents in the residual categories of "don't know" and "no answer", which we coded as missings (see Table B in the Appendix for summary statistics). Accordingly, when using regressions to probe individual-level determinants, we dichotomize the five categories into two groups: respondents, who (strongly) agree with the statement (coded "1"), and respondents, who (strongly) disagree or are undecided (coded "0"). iii That said, we have re-run the analysis using ordered logistic regressions, which produces similar results (see Table $\mathrm{H}$ in the appendix).

In order to test Hypothesis 1, which states that public support for social investment drops considerably once trade-offs are acknowledged, we add two additional dependent variables based on questions from our survey measuring preferences towards spending on "education" and "financial support for families" in an unconstrained scenario (i.e. no trade-offs implied). More specifically, the questions reads: 
Q5 \& Q6: "In the following, I will name several areas of government activity. Please tell me whether you would like to see more or less government spending in each area. Keep in mind that 'more' or 'much more' might require a tax increase." - "Education (Q5)" - "Financial support for families (Q6)".

It could be objected that this unconstrained scenario is not "truly unconstrained" because respondents are reminded of the possibility that a spending increase "might require a tax increase". Yet, as we show elsewhere (AUTHORS, 2017), the reminder about taxes does not have any measurable effect on people's preference compared to a fully unconditional scenario. We can show this by comparing this question to a "truly" unconditional question in our survey, where we do not include the reminder that more spending might increase taxes, and the support levels between the two questions are indistinguishable. We cannot use the latter question for the present analysis, however, because it is part of another survey experiment and therefore only covers part of the sample. We use the weak reminder about tax increases in the primary question in order to make it similar to the commonly used spending questions from the ISSP Role of Government module. All in all, we therefore feel confident about treating the question formulation above (Q5\&Q6) as a "de facto unconditional" baseline category.

Again, we dichotomize responses and distinguish preferences for "more" or "much more" spending (1) and preferences for the "same", "less", or "much less" (0) spending. We match the split-sample questions from above to the respective items, i.e. unconstrained education spending preferences (Q5) for respondents given Q1 or Q2 and unconstrained family spending preferences (Q6) for those given Q3 or Q4. Of course, these items do not constitute a control group in a strict experimental sense, but nevertheless allow us to compare the difference between constrained and unconstrained settings when measuring spending preferences. 
Because of the binary nature of the dependent variables, we estimate multivariate singlelevel logit regressions. We include country fixed-effects and compute country-clustered robust standard errors in order to reflect the fact that the sample is stratified on countries. In the present paper, we focus on associations on the micro-level of attitudes in the pooled sample, while the variation of effects across countries and welfare state regimes will be addressed in future work. We include sampling weights in the descriptive analysis but not in the regression models because weighting can bias the standard errors and is unnecessary when the control variables account for differences in sampling probability (Schmidt-Catran, 2016). Our central explanatory variables related to self-interest capture respondents' beneficiary status (having small kids at home, being a student, unemployed, or retired). Small kids are here those below the age of 10. Because the control variable for kids above the age of 10 also includes potentially adult children still living in the parental household, we do not have strong expectations in this case. In a further step of the analysis we add self-placement on a left-right scale as a measure for ideological predispositions. In addition, we control for household income, educational attainment, gender, age, perceived risk of unemployment, and household size. In the online appendix, we provide additional information on the exact measurement and operationalization of the variables used in the analysis (Table A). Because age correlates heavily with retirement status $(r=0.72)$, we consider age only for those in full-time employment, with the reference group being those in their 30s.

\section{Results}

First, we examine how spending preferences change once trade-offs are introduced. Figure 1 shows the share of respondents agreeing with spending increases on education 
(left) and families (right panel). The first important finding is that support for additional spending on social investment policies drops considerably if this would require cutbacks in compensatory spending, providing strong support for Hypothesis 1 and confirming AUTHORS (2017) for a different set of policy trade-offs. In an unconstrained setting, we see impressive levels of support for spending on social investment: Around 77 percent of respondents support additional spending on education, and 55 percent are supportive of additional financial support for families. As soon as spending trade-offs are introduced, however, support declines strongly. Across the four spending trade-offs, only 17 percent of respondents would agree to a reform that increases social investments at the expense of compensatory policies. A majority disagrees with each of the proposed policy changes. This is not totally surprising, but the new contribution of our paper is to show that an often-held, empirically largely untested assumption in the literature on the "new politics of the welfare state" (Pierson, 2001) in fact has a solid empirical foundation. There is, of course, some cross-country variation in this respect (see Figure A in the appendix), but by and large, the general pattern depicted in Figure 1 also holds across countries.

[Figure 1 here]

Yet, a closer look at Figure 1 reveals that there are considerable differences across the four spending trade-offs, confirming Hypothesis 2: Respondents are much more willing to accept cutbacks in unemployment benefits than in pensions. Every fourth respondent is willing to cut unemployment benefits in order to increase education spending, but this share drops to 10 percent when pensions would be reduced. In other words, the difference between these two compensatory policies is 17 percentage points when the trade-off is about education and 6 percentage points when family spending is concerned. 
This is strong support for our expectation that people are more willing to cut unemployment benefit generosity than pensions, either because of (future-oriented) selfinterest or because of differences in perceived deservingness, as discussed in Hypothesis 2. The differences are less pronounced between investments on families with young children compared to educational investment. This might be related to the fact that both policies address groups that are deemed to be deserving of welfare state support or because the redistributive patterns are more similar for education and family policies than for unemployment benefits and pensions.

In the next step, we examine to what extent this drop in spending support in the case of trade-offs is related to material self-interest based on individual beneficiary status. Hypothesis 3 postulated that the association between self-interest and support for spending on social investment policies should become stronger once we move from an unconstrained to a constrained (trade-off) scenario. Our logistic regression results in Table 1 provide considerable support for this claim: Models 1 and 2 reveal that in the unconstrained scenarios neither having small kids nor being a student is significantly associated with preferences for more spending. This picture changes when moving to the models for spending trade-offs: Respondents with small children are now significantly more likely to support increases in social investment spending (Models 3 and 4), students support increasing education spending (Model 3), and the unemployed (Model 5) and the retired (Model 6) oppose cuts in "their" benefit schemes for the sake of increasing social investment spending. These effects are substantial in size, as indicated by average marginal effect estimates, which allow a comparison of effect sizes across model specifications (see Table D in the Appendix): The likelihood of supporting additional spending increases by 2.7 percentage points for those with small children (Models 3 and 
4) and by 6 percentage points for students (Model 3). Spending support drops by 9.3 percentage points for the unemployed in Model 5 and by 4.5 percentage points for the retired in Model 6. In sum, once spending increases for social investment would be financed by cuts in compensatory spending, considerable differences between different welfare state beneficiary groups come to the fore and self-interest becomes a much stronger predictor of preferences, confirming Hypothesis 3.

[Table 1 here]

Of course, some groups of individuals might benefit from both social investment and higher spending on social transfers (e.g., unemployed single parents in need of public childcare). Some might also expect to need certain social transfers in the future, while favoring social investment in the present (e.g., a student expecting high labor market risks once employed). Given the relatively small size of these 'cross-pressured' groups, however, we cannot directly measure the preferences of these people with our survey data. In general, the 'cross-pressure' effect could contribute to the high levels of opposition to trade-offs. This in fact makes it more likely that we still underestimate the true effects of self-interest. The fact that we find strong and clear effects for the different beneficiary groups indicates that individuals' current situation is more relevant for their attitudes than their potential future needs.

Next, we comment briefly on the control variables. As expected, elderly respondents (those in their 50s and 60s, who are closer to retirement age) oppose expanding social investment spending to the detriment of compensatory spending (Models 3-6). Again, this effect is much more pronounced in the constrained (trade-off) scenarios compared to the 
unconstrained settings (Models 1-2). (Perceived) unemployment risk is negatively associated with cuts in unemployment spending (Model 5), but this effect is not significant. The significant positive effect of having children above the age of 10 in Model 1 (but not in Models 3-6) might appear somewhat surprising at first sight. Yet, as we do not have more specific information about the age and status of these children, these children may be grown-ups living with their parents, working or in youth unemployment, which might account for this unexpected finding. Still, this finding needs to be interpreted with caution.

Higher income goes along with stronger support for social investment increases at the expense of compensation. As expected, there are again significant differences between the constrained and unconstrained settings: In the unconstrained settings, higher income is not (in the case of education) or negatively (in the case of family spending, which is likely to be perceived to be more redistributive) related to spending support. In the constrained setting, high-income respondents, in contrast, are more likely to support education and family spending if this would go along with cutbacks in the more redistributive transfer programs.

Higher educational background should be associated with stronger support for education spending increases (Busemeyer, 2015, ch. 5; Garritzmann, 2015). This association tends to be positive in our data as well, but it is not statistically significant. Moreover, women often benefit less than men from social insurance schemes built around the traditional male-breadwinner model and face particular challenges in combining work and family life at the same time (Esping-Andersen, 2002). Hence, there are good reasons to expect that women support higher spending on social investment policies. However, the results 
show that men are much more likely to accept cutbacks in compensatory spending in order to increase spending on social investments compared to women. Further research is clearly needed here, but a possible explanation is that women might prefer higher levels of public spending on both policy areas as they are found to be more supportive of the welfare state and redistribution in general (Cusack, et al. 2006) and might want to achieve the same levels of compensatory safety nets as men while also favoring social investments.

[Table 2 here]

This leads us towards examining the role of ideology for spending trade-offs (Hypothesis 4). Table 2 shows the direct association of ideology and trade-off preferences. In additional model steps (Models 5-8) we control for general social spending and redistribution preferences to probe the robustness of this association. Overall, the results in Table 2 reveal a strong direct association between ideology and spending support: Leftwing individuals are hostile to spending trade-offs while those identifying themselves with the right are more supportive. This effect is particularly strong for the two models on expanding education spending and on cutting highly redistributive spending on unemployment (Models 1 and 3). Controlling for general social spending and redistribution preferences (Models 5-8) furthermore shows that these two variables moderate a considerable share of the effect of left-right ideology. Individuals with preferences for more social spending reject shifting resources between different areas of welfare spending. Moreover, individuals supporting redistribution are also more likely to oppose spending shifts that would increase education spending or but back unemployment spending. In contrast, the coefficient of ideology is insignificant for trade- 
offs that would imply cut-backs in pension spending (Models 4 and 8). This is likely due to the fact that pension spending is less progressive and has a strong appeal for the middle classes. In sum, respondents subscribing to a left-wing ideology are more solidaristic with all social risk groups and are more opposed to expanding benefits for one group at the expense of another, whereas right-leaning citizens are more supportive of shifting spending from more to less redistributive social policies.

[Figure 2 here]

Next, we turn to the interaction of ideology and material self-interest (Hypothesis 5). Since we are interested in the interactive effects, we interpret the results based on predicted probability plots (Brambor et al., 2006: 74) and report the full models in the appendix (Table F). Figure 2 plots predicted probabilities for spending support using models that include an interaction between left-right ideology and beneficiary group status, differentiating between 'winners' and 'losers' of the proposed reform. 'Winners' are students and those with small children in Model 1 and respondents with small children in Model 2; 'losers' are the unemployed in Model 3 and pensioners in Model 4. The values shown for the 'reference groups' are the average predicted probabilities if the conditioning variables of 'winner' (Models 1 and 2) and 'loser' status (Models 3 and 4) take the value of 0 . The results are the same if we estimate separate models for the two beneficiary groups considered in Model 1 (see Figure B in the appendix).

Hypothesis 5 on the interaction effect between ideology and material self-interest is partially supported: we find significant effects in the expected direction in two of the models (Models 1 and 3). Substantively, these models show that left-wing ideology 
attenuates differences in preferences between winner and loser groups. That is, materialistic self-interest plays less of a role for left-wing voters, while it matters significantly for right-leaning citizens. For example, left-wing students or left-wing parents of small children are no more likely than the remaining population to demand spending increases on education at the expense of compensatory spending (Model 1). Also, while left-wing unemployed respondents most strongly reject cutting unemployment spending in order to finance additional social investment, this opposition is nearly as strong among left-wing individuals without unemployment spells (Model 3). In both models, the predicted probability for left-wing individuals to support a spending trade-off ranges around the value of 10 percent, irrespective of beneficiary status. Put differently, ideology trumps materialistic self-interest.

In contrast and as theorized, right-wing individuals who derive a material benefit from expanding social investment are even more supportive of shifting resources from compensatory to social investment spending. The predicted probability of supporting education spending expansion is 36 percent for right-wing students or parents of small children, but only 20 percent for rightist respondents who would not immediately benefit from such a reform. Similarly, the predicted probability of a right-wing respondent to support cuts in unemployment spending to finance additional social investment is 32 percent, but only 20 percent if this person is unemployed. This difference in terms of predicted probabilities reaches statistical significance at the 95 percent level for those with moderate right-leaning positions (seven on the zero to ten scale). The widening confidence intervals for those at the far-right are to some extent related to the low number of unemployed with a right-wing ideology (see Table G in the Appendix for a cross-tabulation of ideology and beneficiary status). 
The differences in support between affected and unaffected groups are insignificant for those with right-leaning positions with regard to trade-offs involving an expansion of family spending and cut-backs in pensions (Models 2 and 4). This finding indicates that redistributive implications of program characteristics matter beyond the distinction between social investment and compensatory policies. The distributive effects of cash transfers and services for families with small children (Maldonado and Nieuwenhuis, 2015) and the cross-class relevance of public pensions (Busemeyer et al., 2009) appear to cancel out the effects of ideology in these cases. Taken together, the potential of conflict about redistribution between different welfare beneficiary groups is muted among leftwing individuals who jointly reject policy reforms, which would reduce the overall amount of redistribution. In contrast, differences in preferences towards redistributionreducing policy trade-offs based on individual beneficiary status are particularly pronounced for those on the right.

\section{Conclusion}

This paper contributes to recent debates about welfare state reform in 'hard times' by analyzing novel data collected in an original survey on social investment and associated trade-offs. The innovation of this survey is to link respondents' support for additional spending on presumably popular policies to cutbacks in other parts of the welfare state. This new way of measuring spending preferences is in certain ways superior to common approaches in international comparative surveys, but it also has limitations, and we therefore recommend it as a complement to existing research rather than a replacement. Its limitations are that we only look at trade-offs of a particular kind (social investment vs. social transfers), neglecting other policy fields, which citizens might be more inclined 
to sacrifice (such as spending on defense, for instance). Future work could use alternative methodological tools, such as vignette studies or conjoint analyses, to test these claims further in a multidimensional setting. Moreover, in this paper we focused on policy tradeoffs and do not take into account the possibility that citizens might in fact be willing to pay for higher spending with tax increases, although we explore this possibility elsewhere (AUTHORS, 2017). Finally, we only have data for one time-point for a limited number of countries, whereas using panel data on trade-offs would help understanding temporal dynamics. Obviously, results might be different when these parameters are changed.

In general, our analysis demonstrated that social investments are popular, but this popularity has limits. For example, citizens are more willing to accept cutbacks in unemployment benefits rather than pensions in order to finance additional investments in education and family policies. Not surprisingly, we also find that those who benefit from social investment spending, i.e. students and parents with small children, are more willing to accept cutbacks in pensions and unemployment benefits in order to increase spending on social investment, whereas the potential losers of this deal, i.e. retired persons and to a lesser extent the unemployed, are opposed. Ideological predisposition also matter in the sense that traditional supporters of the welfare state are more inclined to reject cutbacks in unemployment benefits and pensions, even if this would lead to additional spending on social investment policies. We also found evidence for interaction effects between ideology and material self-interest in line with recent work (Brooks and Manza, 2013; Margalit 2013) on social policy preferences.

This finding has crucial implications for the future political viability of the social investment state. Our findings imply that - while it is true that left-leaning citizens are 
more in favor of social investment - it might actually be easier for right-leaning politicians to "recalibrate" welfare states towards social investment because their voters are more willing to accept accompanying cutbacks in other ("old") social policies. Left-wing politicians could become stuck between a rock and a hard place: while their voters demand the expansion of social investments, they are not willing to accept policy tradeoffs. One way out of this trap might be to increase taxes or public debt, i.e. to expand the size of the cake rather than aim at a different distribution. Yet, in a time of "permanent fiscal austerity" (Pierson, 2001) and an omnipresent political discourse around debt- taxreductions (Blyth, 2013; Haffert and Mehrtens, 2015), the associated political costs of such a strategy might be prohibitively high. In any case, our results imply that welfare state modernization implies different political dynamics for left- and right-wing parties. 


\section{References}

Ansell, B. W. (2010). From the ballot to the blackboard - the redistributive political economy of education. Cambridge: Cambridge University Press.

Becker, R., and Hecken, A.E. (2009). Why Are Working-Class Children Diverted from Universities? An Empirical Assessment of the Diversion Thesis. European Sociological Review 25, 2: 233-250.

Berinsky, A.J. (2017). Measuring Public Opinion with Surveys. Annual Review of Political Science, 20: 309329.

Blyth, M. (2013). Austerity: The History of a Dangerous Idea. Oxford: Oxford University Press.

Boeri, T. , Börsch-Supan, A. and Tabellini, G. (2001). Would you like to shrink the welfare state? A survey of European citizens. Welfare State Reform, 16, 32: 8-50.

Bonoli, G. (2007). Time matters: Postindustrialization, new social risks, and welfare state adaptation in advanced industrial democracies. Comparative Political Studies 40, 5: 495-520.

Bonoli, G. (2013). The Origins of Active Social Policy: Labour Market and childcare policies in a comparative perspective. Oxford: Oxford University Press.

Brambor, T., Clark, W. R., and Golder, M. (2006). Understanding interaction models: Improving empirical analyses. Political Analysis, 14, 1: 63-82.

Brooks, C. and Manza, J. (2006). Why do welfare states persist? Journal of Politics, 68, 4: 816-827.

Brooks, Clem and Manza, J. (2013) A Broken Public? Americans' Responses to the Great Recession. American Sociological Review 78, 5: 727-748.

Busemeyer, M. R. (2012). Inequality and the political economy of education: An analysis of individual preferences in OECD countries. Journal of European Social Policy, 22, 3: 219-240.

Busemeyer, M. R. (2015). Skills and inequality: Partisan politics and the political economy of education reforms in Western welfare states. Cambridge: Cambridge University Press.

Busemeyer, M. R., Goerres, A. and Weschle, S. (2009). Attitudes towards redistributive spending in an era of demographic ageing: The rival pressures from age and income in 14 OECD countries. Journal of European Social Policy, 19, 3: 195-212.

Busemeyer, M. R. and Neimanns, E. (2017). Conflictive Preferences Towards Social Investments and Transfers in Mature Welfare States: The Cases of Unemployment Benefits and Childcare Provision. Journal of European Social Policy, 27, 3: 229-246.

Citrin, J. (1979). Do people want something for nothing: Public opinion on taxes and government spending. National Tax Journal, 32, 2: 113-129.

Cusack, T., Iversen, T. and Rehm, P. (2006). Risks at work: The demand and supply sides of government redistribution. Oxford Review of Economic Policy, 22, 3: 365-389.

De la O, A. and Rodden, J. A. (2008). Does religion distract the poor? Income and issue voting around the world. Comparative Political Studies, 41, 4: 437-476.

Elliot, A. J. and Devine, P. G. (1994). On the motivational nature of cognitive dissonance: Dissonance as psychological discomfort. Journal of personality and social psychology, 67, 3: 382.

Esping-Andersen, G. (2002). Why We Need a New Welfare State. Oxford: Oxford University Press.

Festinger, Leon. (1957). A theory of cognitive dissonance. Stanford: Stanford University Press.

Garritzmann, J. L. (2015). Attitudes towards student support: How positive feedback-effects prevent change in the four worlds of student finance. Journal of European Social Policy, 25, 2: 139-158.

Garritzmann, J.L., Häusermann, S., Palier, B., and Zollinger, C. (2017). WOPSI: The World Politics of Social Investment. LIEPP Working Paper, no 64.

Genschel, P. (2004). Globalization and the Welfare State: A Retrospective. Journal of European Public Policy 11, 4: 613-636.

Giger, N. and Nelson, M. (2013). The Welfare State or the Economy? Preferences, Constituencies, and Strategies for Retrenchment. European Sociological Review, 29, 5: 1083-1094.

Goerres, A., and Prinzen, K. (2012). Can we improve the measurement of attitudes towards the welfare state? A constructive critique of survey instruments with evidence from focus groups. Social Indicators Research, 105: 515-34.

Haffert, L. and Mehrtens, P. (2015). From Austerity to Expansion? Consolidation, Budget Surpluses, and the Decline of Fiscal Capacity. Politics and Society, 43, 1: 119-148.

Hansen, J.M. (1998). Individuals, Institutions, and Public Preferences over Public Finance. American Political Science Review, 92, 3: 513-531.

Hasenfeld, Y. and Rafferty, A. J. (1989). The Determinants of Public Attitudes toward the Welfare State. Social Force, 67, 4: 1027-1048. 
Häusermann, S., Schwander, H. and Kurer, T. (2015). High-skilled outsiders? Labor market vulnerability, education and welfare state preferences. Socio-Economic Review, 13, 2: 235-258.

Hemerijck, A. (2013). Changing welfare states. Oxford: Oxford University Press.

Iversen, T. and Soskice, D. (2001). An asset theory of social policy preferences. American Political Science Review, 95, 4: 875-894.

Jost, J. T., Federico, C. M. and Napier, J. L. (2009). Political ideology: Its structure, functions, and elective affinities. Annual review of psychology, 60: 307-337.

Hemerijck, A. (2017). The Uses of Social Investment. Oxford: Oxford University Press.

Jakobsen, T. G. (2010). Public versus Private: The Conditional Effect of State Policy and Institutional Trust on Mass Opinion. European Sociological Review, 26, 3: 307-318.

Jaeger, M.M. (2006). What Makes People Support Public Responsibility for Welfare Provision: Self-Interest or Political Ideology? A Longitudinal Approach. Acta Sociologica 49, 3: 321-338.

Jaeger, M.M. (2009). United but Divided: Welfare Regimes and the Level and Variance in Public Support for Redistribution. European Sociological Review, 25, 6: 723-737.

Jordan, J. (2013). Policy feedback and support for the welfare state. Journal of European Social Policy, 23, 2: 134-148.

Kangas, O.E. (1997). Self-interest and the common good: The impact of norms, selfishness and context in social policy opinions. The Journal of Socio-Economics, 26, 5: 475-494.

Kuklinski, J.H., Quirk, P.J., Jerit, J., Rich, R.F. (2001). The Political Environment and Citizen Competence. American Journal of Political Science, 45, 2: 410-424.

Kumlin, S. (2014). Policy feedback in political context: Unemployment benefits, election campaigns, and democratic satisfaction. In: Kumlin, S. and Stadelmann-Steffen, I. (Eds.), How Welfare States Shape the Democratic Public. Policy Feedback, Participation, Voting, and Attitudes. Cheltenham, UK; Northhamption, USA: Edward Elgar, pp. 181-197.

Kumlin, S. and Stadelmann-Steffen, I., (2014). How Welfare States Shape the Democratic Public. Policy Feedback, Participation, Voting, and Attitudes. Cheltenham, UK; Northhamption, USA: Edward Elgar.

Lupu, N. and Pontusson, J. (2011). The structure of inequality and the politics of redistribution. American Political Science Review, 105, 2: 316-336.

Maldonado, L.C. and Nieuwenhuis, R. (2015). Family policies and single parent poverty in 18 OECD countries, 1978-2008. Community, Work \& Family, 18, 4: 395-415.

Margalit, Y. (2013). Explaining social policy preferences: Evidence from the great recession. American Political Science Review, 107, 1: 80-103.

Meuleman, B. and Chung, H. (2012). Who Should Care for the Children? Support for Government Intervention in Childcare. In: Ervasti, H., Andersen, J. G., Fridberg, T. and Ringdal, K. (Eds.), The Future of the Welfare State: Social Policy Attitudes and Social Capital in Europe. Cheltenham: Edward Elgar, pp. 107-133.

Morel, N., Palier, B. and Palme, J. (2012). Towards a social investment welfare state: Ideas, policies and challenges. Bristol: The Policy Press.

Naumann, E., Buss, C. and Bähr, J. (2015). How unemployment experience affects support for the welfare state: a real panel approach. European Sociological Review, 32, 1: 81-92.

Owens, Lindsay A. and Pedulla, D.S. (2014). Material Welfare and Changing Political Preferences: The Case of Support for Redistributive Social Policies. Social Forces 92, 3: 1087-1113.

Pierson, P. (2001). The new politics of the welfare state. Oxford: Oxford University Press.

Rehm, P. (2009). Risks and redistribution an individual-level analysis. Comparative Political Studies, 42, 7: 855-881.

Rehm, P., Hacker, J. S. and Schlesinger, M. (2012). Insecure alliances: Risk, inequality, and support for the welfare state. American Political Science Review, 106, 2: 386-406.

Roosma, F., Gelissen, J., and Van Oorschot, W. (2013). The Multidimensionality of Welfare State Attitudes: A European Cross-National Study. Social Indicators Research, 113: 235-255.

Rueda, D. (2006). Social Democracy and Active Labour-Market Policies: Insiders, Outsiders and the Politics of Employment Promotion. British Journal of Political Science, 36, 3: 385-406.

Schmidt-Catran, A. W. (2016). Economic inequality and public demand for redistribution: Combining crosssectional and longitudinal evidence. Socio-Economic Review, 14, 1: 119-140.

Svallfors, S. (2012). Contested welfare states: Welfare attitudes in Europe and beyond. Stanford: Stanford University Press.

Vandenbroucke, F. and Vleminckx, K. (2013). Disappointing poverty trends: is the social investment state to blame? Journal of European Social Policy, 21, 5: 450-471.

Van Lancker, W. (2013). Putting the Child-Centred Investment Strategy to the Test: Evidence for the EU27. European Journal of Social Security, 15, 1: 4-27. 
Van Oorschot, W. (2006). Making the difference in social Europe: deservingness perceptions among citizens of European welfare states. Journal of European Social Policy, 16, 1: 23-42.

Zaller, John. (1992). The Nature and Origins of Mass Opinion. Cambridge: Cambridge University Press. 
Figure 1: Shares of respondents supporting increases in social investment spending unconstrained spending preferences and when implying cuts in compensatory spending

\section{Preferences towards spending increases}

Share of respondents agreeing with policy scenario
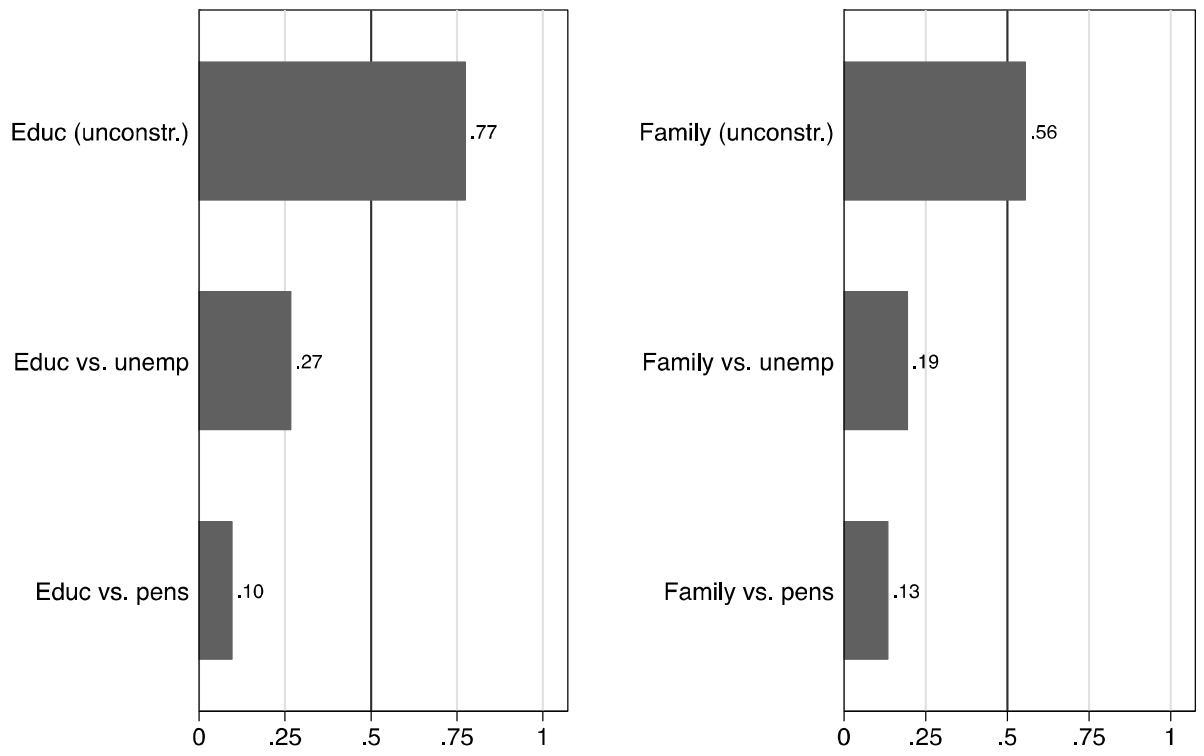
Table 1: Logistic regressions: Support for social investment - unconstrained spending preferences and when implying cuts in compensatory spending; maximum likelihood estimates

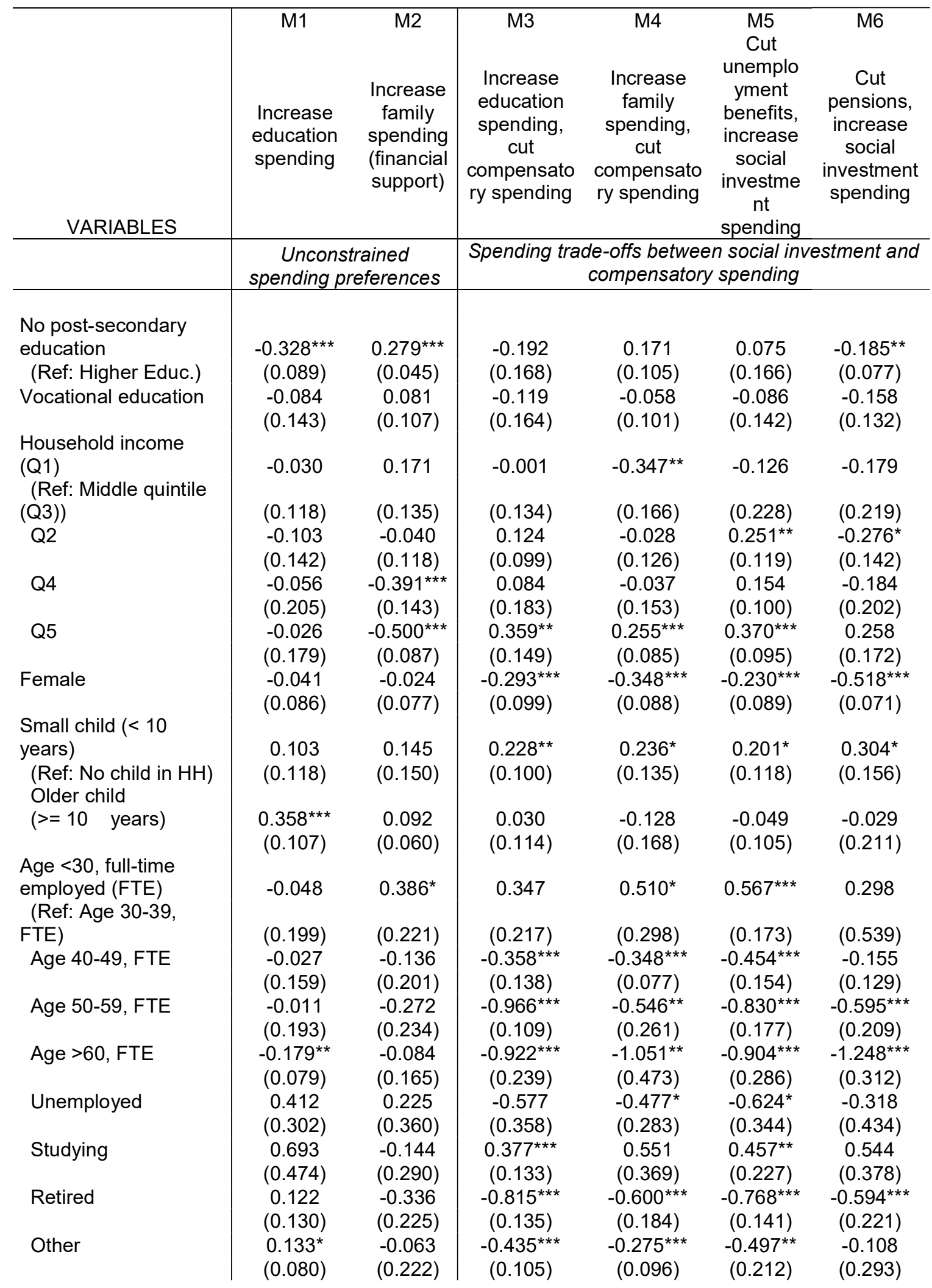




\begin{tabular}{|c|c|c|c|c|c|c|}
\hline Risk of unemployment & $\begin{array}{c}0.084 \\
(0.172)\end{array}$ & $\begin{array}{l}-0.122 \\
(0.143)\end{array}$ & $\begin{array}{c}-0.362 \\
(0.265)\end{array}$ & $\begin{array}{c}0.028 \\
(0.095)\end{array}$ & $\begin{array}{c}-0.262 \\
(0.273)\end{array}$ & $\begin{array}{c}0.002 \\
(0.132)\end{array}$ \\
\hline $\begin{array}{l}\text { Cohabit } \\
\text { (Ref: one adult } \\
\text { household) }\end{array}$ & $\begin{array}{l}-0.022 \\
(0.071)\end{array}$ & $\begin{array}{l}0.092 \\
(0.079)\end{array}$ & $\begin{array}{l}0.055 \\
(0.138)\end{array}$ & $\begin{array}{c}-0.251^{* * *} \\
(0.088)\end{array}$ & $\begin{array}{l}-0.002 \\
(0.102)\end{array}$ & $\begin{array}{l}-0.254^{* *} \\
(0.108)\end{array}$ \\
\hline $\begin{array}{l}\text { Country dummies } \\
\text { Trade-off dummy } \\
\text { Pseudo R2 }\end{array}$ & 0,074 & 0,118 & $\begin{array}{l}\text { Yes } \\
\text { Yes } \\
0,094\end{array}$ & $\begin{array}{l}\text { Yes } \\
\text { Yes } \\
0,070\end{array}$ & $\begin{array}{l}\text { Yes } \\
\text { Yes } \\
0,075\end{array}$ & $\begin{array}{l}\text { Yes } \\
\text { Yes } \\
0,043\end{array}$ \\
\hline Observations & 3,931 & 3,849 & 3,892 & 3,870 & 3,929 & 3,833 \\
\hline
\end{tabular}

Country-clustered robust standard errors in parentheses.

${ }^{* * *} p<0.01,{ }^{* *} p<0.05,{ }^{*} p<0.1$ 
Table 2: Logistic regressions: Effects of ideology on support for social investment when implying cuts in compensatory spending; maximum likelihood estimates

\begin{tabular}{l|cccc}
\hline & $\begin{array}{c}\text { Increase } \\
\text { education } \\
\text { spending, cut } \\
\text { compensatory } \\
\text { spending }\end{array}$ & $\begin{array}{c}\text { Increase } \\
\text { family } \\
\text { spending, cut } \\
\text { compensatory } \\
\text { spending }\end{array}$ & $\begin{array}{c}\text { Cut } \\
\text { unemployment } \\
\text { benefits, } \\
\text { increase social } \\
\text { investment } \\
\text { spending }\end{array}$ & $\begin{array}{c}\text { Cut pensions, } \\
\text { increase social } \\
\text { investment } \\
\text { spending }\end{array}$ \\
\hline Right-wing ideology & $M 1$ & $M 2$ & $M 3$ & $M 4$ \\
\hline & $0.112^{* * *}$ & $0.089^{* * *}$ & $0.134^{* * *}$ & 0.045 \\
& $(0.026)$ & $(0.021)$ & $(0.021)$ & $(0.029)$ \\
\hline Right-wing ideology & $M 5$ & $M 6$ & $M 7$ & $M 8$ \\
\hline Social spending preferences & $0.063^{* * *}$ & $0.064^{* * *}$ & $0.089^{* * *}$ & 0.028 \\
& $(0.021)$ & $(0.023)$ & $(0.015)$ & $(0.030)$ \\
Redistribution preferences & $-0.395^{* * *}$ & $-0.346^{* * *}$ & $-0.442^{* * *}$ & $-0.250^{* *}$ \\
& $(0.068)$ & $(0.065)$ & $(0.101)$ & $(0.107)$ \\
& $-0.094^{* * *}$ & 0.005 & $-0.120^{* * *}$ & 0.094 \\
& $(0.027)$ & $(0.026)$ & $(0.024)$ & $(0.059)$ \\
\hline
\end{tabular}

Country-clustered robust standard errors in parentheses; all models include the same independent variables as those models reported in Table 1. See Table $E$ in the appendix for the full models.

${ }^{* * *} p<0.01,{ }^{* *} p<0.05,{ }^{*} p<0.1$ 
Figure 2: Predicted probabilities of support for social investment when implying cuts in compensatory spending - interactions between selfinterest and ideology for affected groups

Model 1: Education vs. compensation

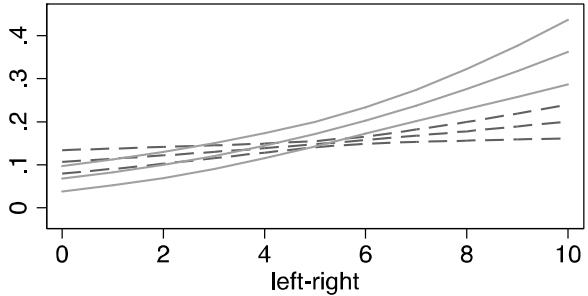

--- Ref. group $\longrightarrow$ Kids/students

Model 3: Unemployment vs. soc.inv.

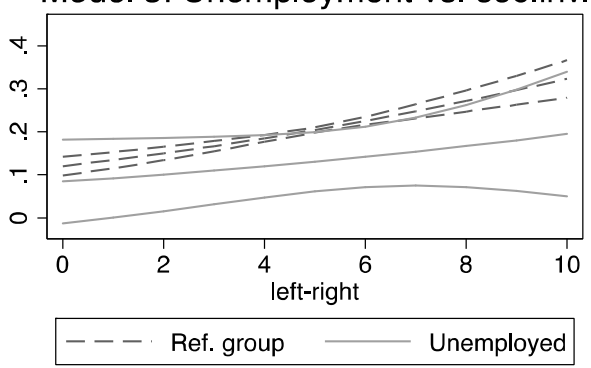

Model 2: Family vs. compensation

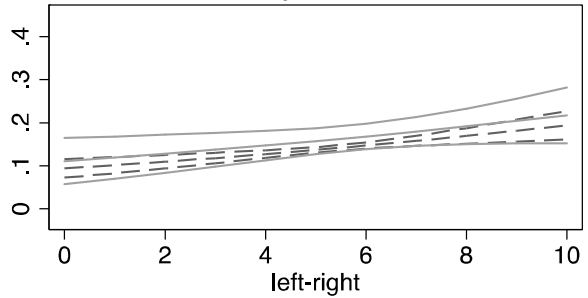

---- Ref. group $\longrightarrow$ Kids

Model 4: Pensions vs. soc.inv.

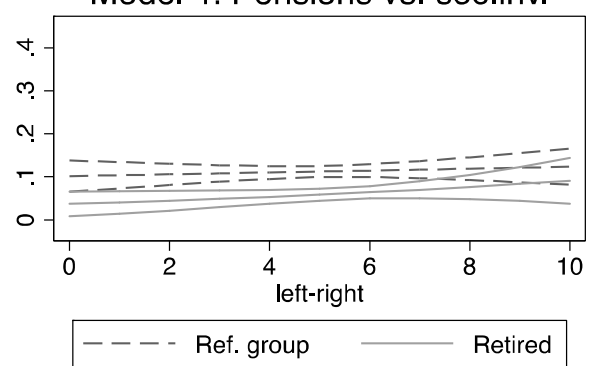

Note: Predicted probabilities and 95\% confidence intervals are based on logistic regressions in Table $\mathrm{F}$ in the online appendix. The values shown for the 'reference groups' are the average predicted probabilities if the conditioning variables of 'winner' (Models 1 and 2) and 'loser' status (Models 3 and 4) take the value of 0 . 


\section{Notes}

${ }^{i}$ Note that with regard to family policies we not only consider spending in kind, such as childcare, but also cash transfers targeted to families with young children (see operationalization below). The latter can be expected to be more redistributive than the former as it has strong poverty reducing effects, whereas access to childcare is often socially stratified (Van Lancker, 2013; Maldonado and Nieuwenhuis, 2015).

ii More information on the survey can be found in a detailed background report (LINK REMOVED FOR THE REVIEW PROCESS).

iii The results largely stay the same if the middle category is excluded. 